\title{
TYPES OF CONTRACEPTIVES PRACTICED BY THE WOMEN ATTENDING MODEL FAMILY PLANNING CLINIC AT DHAKA MEDICAL COLLEGE HOSPITAL, DHAKA
}

\author{
MAHMOOD AR ${ }^{1}$, HOQUE SR $^{2}$, ARA $^{3}$, KARIM SR $^{4}$, FERDOUSI SK $^{5}$, SULTANA R ${ }^{6}$
}

\begin{abstract}
:
A cross-sectional descriptive study was conducted among the married women of reproductive age attending the Model Family Planning Clinic at Dhaka Medical College Hospital (DMCH), Dhaka, and seeking contraceptives, and the aim of the study was to find out the types of contraceptives practiced by the women. A total of 300 respondents were interviewed. Data were collected through a semi-structured questionnaire by face-to-face interview. The mean age of the respondents was 27.5 years ( \pm 6.17 years). Most of them (61\%) were literate but $15.33 \%$ were illiterate and $23.64 \%$ respondents were able to write their name only. Most of the respondents (about 75\%) were housewives. Their mean monthly income was 7673.58 taka $( \pm 6512.91$ taka). Mean duration of their married life was 12.33 years ( \pm 6.04 years) and maximum respondents (30.33\%) had duration of married life ranging from 6-10 years. Majority of them (45\%) was using OCP. Significant percentage (35\%) was using contraceptives for 1-20 months. Among the contraceptive users $44 \%$ experienced some problems, of which menstrual problem was more common (45\%). The study concluded that social awareness about contraception campaigning programme should be strengthened, with special emphasis to the newly married couple.
\end{abstract}

Key words: contraception, contraceptive practice, contraceptive prevalence rate (CPR), net reproductive rate (NRR).

J Dhaka Med Coll. 2011; 20(1) : 112-115.

\section{Introduction:}

Widespread contraceptive practice has brought revolutionary changes in the population trend of the world and has enabled men to take remarkable steps forward toward achieving a higher standard of life. Acceptance of contraception itself is guided by numerous determinants for example: reproductive preferences, availability, beliefs ${ }^{1} \&$ social bindings and also a variety of socio demographic factors such as poverty, illiteracy, fertility ${ }^{2}$. In Bangladesh, use of almost all modern methods has been rising over time, with the increase in the use of pills being pronounced during the 1986-91 period. Condoms registered the next highest ever-used rate. Service statistics of the MIS unit of the Directorate of Family Planning also show that the use of sterilization and that of IUDs has been on the decline, while use of oral pills and injectable methods has been rising ${ }^{3}$. The contraceptive prevalence rate in Bangladesh has increased almost seven folds since 1975 from $8 \%$ to $54 \%$ of married women ${ }^{4}$. Bangladesh is the only country among the 20 poorest countries

1. Dr. Afzalur Rahman Mahmood, Lecturer, Department of Community Medicine, Dhaka Medical College, Dhaka.

2. Dr. Syeda Rumana Hoque, Medical Officer, Department of Community Medicine, Dhaka Medical College, Dhaka.

3. Dr. Rowshan Ara, Assistant Professor, Department of Community Medicine, Dhaka Medical College, Dhaka.

4. Dr. Sabedur Reza Karim, Lecturer, Department of Community Medicine, Shaheed Suhrawardy Medical College, Dhaka.

5. Dr. S.K. Ferdousi, Assistant Professor, Department of Community Medicine, Dhaka Medical College, Dhaka. 6. Dr. Razia Sultana, Lecturer, Department of Community Medicine, Dhaka Medical College, Dhaka.

Correspondence : Dr. Afzalur Rahman Mahmood, Lecturer, Department of Community Medicine, Dhaka Medical College, Dhaka. 
where sustained fertility reduction has taken place over the past 15 years, despite slow socio-economic development. The decline in fertility over the past two decades is equal to three quarter of the decline needed to achieve the replacement level fertility ${ }^{5}$. Net Reproductive Rate (NRR)=1 can be achieved only, if at least 60 percent of eligible couples effectively use contraception ${ }^{6}$. It was found that female education has relatively more effect on practice of contraception than to male. It was also found that employment outside have increased the use of contraception among women and among those who have no formal education ${ }^{7}$.

The vision of present Health, Nutrition and Population Sector Program (HNPSP: July 2003June 2006) is to achieve $N R R=1$ as soon as possible but no later than $2015^{8}$ However Bangladesh still rely on single method like oral pill. It is recommended that greater efforts must be made to achieve more of a balance of methods, increasing especially cost effective and long term contraceptive methods ${ }^{4}$.

This study has made an attempt to identify the prevalence of contraceptive methods in our community and find out some factors influencing acceptance of these methods by the eligible couples which may provide necessary information to further improve the present scenario and may help to achieve planned target ${ }^{9}$.

\section{Materials \& Methods:}

The study was conducted at Model Family Planning Clinic at Dhaka Medical College Hospital (DMCH). The study was carried out from November 2005 to April 2006. Married women attending at that department were the study population and a total of 300 were interviewed. As $\mathrm{DMCH}$ is situated in the centre of Dhaka and here people came from various regions and of variable classes. But as seen in this study group higher educational and higher income group women are less frequently came here. This cross-sectional study gives a view of the pattern of contraceptives uses and its influencing factors and effects. Relevant data were collected, checked and verified. Important tables and graphs were prepared on the basis of relevant findings to the study.

\section{Results:}

Data were collected from 300 married women attending at Model Family Planning Clinic of $\mathrm{DMCH}$. Their socio-economic variables are presented in Table-I. Mean age of the respondents was 27.5 years ( \pm 6.17 years). Most of them (29.33\%) were in 21-25 year age group. Majority of them $(28.66 \%)$ were educated up to vi-x. Three fourth $(74.66 \%)$ of the respondents were housewives. Their mean monthly income was Tk. 7673.58 \pm 6512.91 Taka. Total 300 respondents were categorized into 5 groups according to their duration of their married life. About one third (30.33\%) of the respondents had the duration of married life from 6-10 years. Among the total respondents 10 women did not give birth of any children till the time of interview. Among the rest more than 50\% had 1-2 living children. About 65\% respondent's age of last child were in between 1-5 years (Table II). Figure 1 depicts OCP was the most commonly practiced contraceptives $(45 \%)$. Next were injectable (34.67\%), Implant (11.33\%) and Cu$\mathrm{T}(4.33 \%)$. About one third of the OCP users were in 21-25 year age group. Same picture $(30 \%)$ found also in case of injectable contraceptive. But in case of implant, majority $(38.23 \%)$ was in 31-35 year age group. Among the respondents who had undergone tubectomy $(n=8), 50 \%$ were in the age group of $36-40$ years. Near about half of the respondents (56\%) did not complain of any problem (Fig.2). Among the rest (44\%), majority complained for menstrual problem. Next problems were as follows, vertigo (28\%), lower abdominal pain $(16 \%)$, weakness $(10 \%)$, headache $(13 \%)$, nausea and vomiting, weight gain and others. There were multiple responses found about the complaints. 
Table-I

Socio-demographic characteristics of the respondents

\begin{tabular}{|c|c|c|c|}
\hline Variables & Frequency & Mean \&SI & \\
\hline \multirow[t]{7}{*}{ Age(in yr) } & $16-20$ & $39(13)$ & $27.5+6.17$ \\
\hline & $21-25$ & $88(29.33)$ & \\
\hline & $26-30$ & $72(24)$ & \\
\hline & $31-35$ & $70(23.33)$ & \\
\hline & $36-40$ & $27(09)$ & \\
\hline & $41+$ & $4(1.33)$ & \\
\hline & Total & $300(100)$ & \\
\hline \multirow{9}{*}{$\begin{array}{l}\text { Level of } \\
\text { education }\end{array}$} & Illiterate & 46(15.33) & \\
\hline & $\begin{array}{l}\text { Able to } \\
\text { write name }\end{array}$ & $71(23.66)$ & \\
\hline & $\mathrm{I}-\mathrm{V}$ & $58(19.33)$ & \\
\hline & VI-X & $86(28.66)$ & \\
\hline & $\mathrm{SSC}$ & $23(7.66)$ & \\
\hline & HSC & $8(2.66)$ & \\
\hline & Graduation & $8(2.66)$ & \\
\hline & $\&$ above & & \\
\hline & Total & $300(100)$ & \\
\hline \multirow{4}{*}{$\begin{array}{l}\text { Monthly } \\
\text { income } \\
\text { (in Taka) }\end{array}$} & $<3000$ & $16(5.33)$ & $7673.58+6512.91$ \\
\hline & $3000-10,000$ & $243(81)$ & \\
\hline & $>10,000$ & $41(13.66)$ & \\
\hline & Total & $300(100)$ & \\
\hline
\end{tabular}

${ }^{*}$ Figure in parenthesis indicate \%

Table-II

Obstetrical history of the respondents

\begin{tabular}{llcl}
\hline Variables & & Frequency & Mean\& SD \\
\hline Duration & $1-5$ & $38(12.66)$ & $12.33+6.04$ \\
of married & $6-10$ & $91(30.33)$ & \\
life (in year) & $11-15$ & $80(26.66)$ & \\
& $16-20$ & $55(18.33)$ \\
& $=>21$ & $36(12)$ \\
Number of & Total & $300(100)$ \\
living & $3-4$ & $169(58.27)$ \\
children & $>4$ & $110(37.93)$ \\
& Total & $11(3.79)$ \\
Age of the $<1$ & $11(3.79)$ & $290(100)$ \\
last child & $1-5$ & $190(65.51)$ \\
(in year) & $6-10$ & $64(22.06)$ \\
& $11-15$ & $18(6.2)$ \\
& $16-20$ & $7(2.41)$ \\
\hline
\end{tabular}

*Figure in parenthesis indicate \%

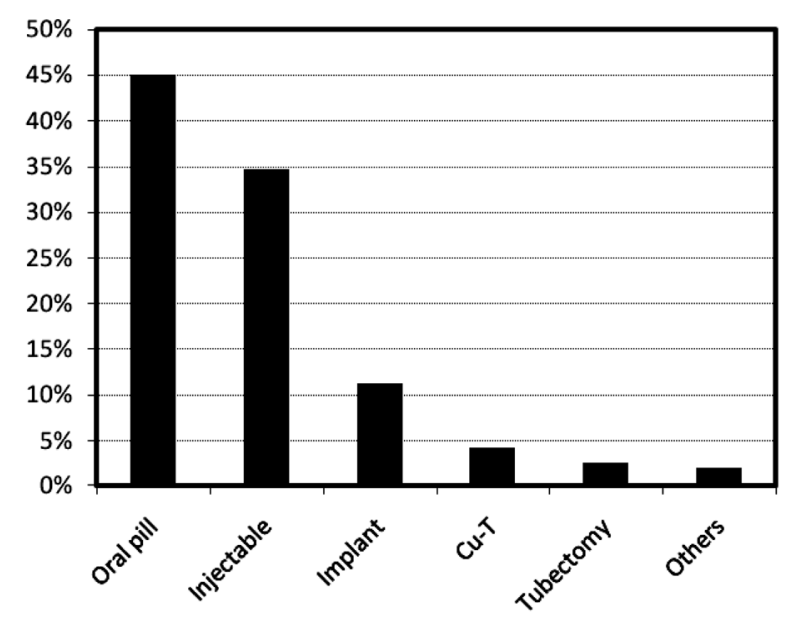

Fig.-1: Types of contraceptives practiced by the respondents

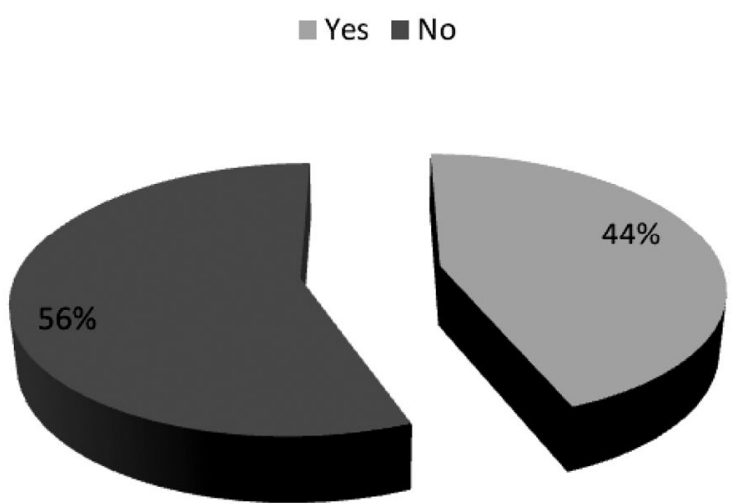

Fig.-2: Problems faced during contraceptive practice

\section{Discussion:}

Population problem is a burning problem for Bangladesh. The use of contraceptive is the most important factor affecting fertility. It is felt that in spite of existence of an official family planning programme, contraceptive practice among the Bangladeshi couples is not increasing at desirable rate ${ }^{10}$. In this current study, the majority (29.33\%) was in between 21-25 years; with a decline in use below 20 and above 35 years. The findings correspond with that of A.H.M. Hakim ${ }^{11}$, where he found contraceptive acceptance rate increased up to 30-34 years with a decline afterwards. Study conducted by Bangladesh Medical Association ${ }^{12}$ also found the highest CPR in 31-35 years age group. 
We also found that majority (46\%) was oral pill user and in every individual age group, it has been explored as the most acceptable contraceptive method. Other study findings ${ }^{12,13,14}$ are also consistent with our result. The analysis of these results may have the explanation that the use of oral contraceptive is regarded as the most popular one as it does not require any hospital service and perhaps it occupies the largest publicity than any other methods. The maximum (30.33\%) women in this study have marital life of $6-10$ years. Only $12 \%$ have the duration of married life ranging from 21-25 years and in only $12.66 \%$, it ranges from 1-5 years. According to an ICDDR,B publication ${ }^{15}, 50 \%$ of the newly wed couples were found as non users of contraceptive methods. The findings may be explained in this way that currently wed people have a dream to have children. And after a considerable period of time there may be a relatively decreased chance of giving birth to a child as the couples are more engaged with many other activities, the practice of contraceptive use declines.

This study gives an outlook about the practice of contraceptive use among the women attending the Model Family Planning Clinic, $\mathrm{DMCH}$. Our study population is a combination of women of different modalities attending at a specified place for getting contraceptive facilitation who may not be regarded as a representative of the whole community. Any way, every couple should have obvious knowledge regarding different contraceptive methods and adopt any of them according to their demand from very early of their conjugal life. The pathway of development will be then smoother for the nation to move forward.

\section{References:}

1. Akter HH, Ahmed S. Determinants of contraceptive use dynamic in rural Bangladesh. BIRPERHT, Dhaka. 1991.

2. Azam SAS. Contraceptive acceptance among selected low socioeconomic group having at least two children. [MPH Dissertation]. NIPSOM, Dhaka: University of Dhaka. 2002.
3. Khuda BE, Whitney, Edson E, Barkat A. The national FP-MCHIEC strategy for Bangladesh, 1993-2000. Dhaka: Ministry of Health and Family Welfare, Government of the People's Republic of Bangladesh.

4. Mitra and Associates and Measure DHS+ORC Macro International Inc. Bangladesh demographic and Health Survey 1999-2000. Dhaka, NIPORT. 2000 .

5. Jamil FA. Clinical contraceptive programme and its quality improvement issue- keynote paper. 2005.

6. Park K. Park's Text Book of Preventive and Social Medicine. $18^{\text {th }}$ ed. Jabalpur: Banarsidas Bhanot Publishers; 2005: p. 358-81.

7. Rahman AKM. A study on contraceptive practice among doctors of Mymensingh Medical College Hospital. [MPH Dissertation]. NIPSOM, Dhaka: University of Dhaka. 2001.

8. Rahman MM. Knowledge regarding long term and short term methods of contraception among rural married women in a selected upazila. [MPH Dissertation]. NIPSOM, Dhaka: University of Dhaka. 2005.

9. Nayer I. Acceptance of long term contraceptive methods and its related factors among the eligible couples in a selected union. [MPH Dissertation]. NIPSOM, Dhaka: University of Dhaka. 2002.

10. Begum HA. Study on factor influencing the acceptance of different contraceptive methods among the clients attending at Mohammadpur fertility centre. [MPH Dissertation]. NIPSOM, Dhaka: University of Dhaka. 2000.

11. Hakim AHMN. Contraceptive practice among eligible couples of class III and class IV employees, residing in Mohakhali, Dhaka-1212. [MPH Dissertation]. NIPSOM, Dhaka: University of Dhaka. 1995.

12. Bangladesh Medical Association. Current Contraceptive use and its determinants in periurban community of Bangladesh. Bangladesh Med J 2000; 30(1):

13. Shahida A. Knowledge of newly married couples on contraceptive methods and their use. [MPH Dissertation]. NIPSOM, Dhaka: University of Dhaka. 2004.

14. Operationalizing ESP delivery in the public sector in Dhaka city, result and discussion. ICDDR,B Publication. 2005.

15. Determinants of contraceptive use among married teenage women and new couples. ICDDR,B Publication. 2005. 